\title{
Analysis of the Impact of EU Pesticide Residue limit Barriers on Chinese Tea Export
}

\author{
Wang Bo, Qiu Juan, Tang Xiaoshan \\ Economic and Trade Department of Fuzhou University of International Studies and Trade \\ Fuzhou, Fujian 350202 \\ Concord University College Fujian Normal University
}

\begin{abstract}
Under the trend of the increasingly globalized economy, the trade contact of various countries has become the main impetus for economic globalization. In the export and import trade of various countries, the degree of emphasis on green trade barriers is far higher than other trade barriers. As a kind of weak industry, tea has been restricted by pesticide residue limit standard in export. This paper adopts gravity model to conduct regression analysis on the trade status of Chinese tea in EU market, and the objective is to explore how is the impact of agricultural residue on Chinese tea exported to $\mathbf{E U}$, and meanwhile, put forward relevant suggestions and countermeasures, to promote the export of Chinese tea.
\end{abstract}

Keywords-Pesticide residue limit; Tea export; Gravity model

\section{INTRODUCTION}

In tea trade, pesticide residue limit is one of the highest levels of environment trade barriers. In high-end tea market, the relative price for tea from other places is lower than that of EU, and the profit rate is also lower; Chinese producers prefer to export their own tea to EU. Along with the constant promotion of people's cognition about food safety, EU has newly released the pesticide residue limit index, expanded the inspection range and released a series of management regulations. From 2000 when EU implemented the new pesticide residue limit standard to 2014, Chinese tea pesticide residues terms for EU had reached to 470, which had become the biggest trade barrier for exporting Chinese tea to EU. It is of certain realistic significance to the continuous increase of tea trade in our country and the interest maintenance of tea enterprises and tea peasants considering understanding EU pesticide residue limit regulations, analyzing the impact on tea trade of our country after its implementation, and the proposal about how to promote Chinese tea export.

\section{ANALYSIS ON THE CURRENT STATUS OF CHINESE TEA EXPORTED TO EU}

\section{A. Brief Introduction about Pesticide Residue Limit Standard of EU Tea}

The sales volume of tea is less than the output, so the export country has always been in a passive position. EU is an important place of import for tea, and also the first region that implements environment trade barrier measures for tea import. In the recent ten years, due to the maintenance for the interest of consumers, EU released a series of strict tea pesticide residue limit regulations. In 2000, EU firstly made a major adjustment about the pesticide residue limit, which is largely increased. After that, EU would update it almost every year and each year it would become stricter. In 2005, EU released Rule EC NO 396/2005 Regulation, and the objective was to handle the excessively messy status of pesticide residue limit management laws. Then, EU constantly released regulations as per the mode of rules to modify the regulation. In 2008, 170 types of pesticide were increased in the tea inspection project, which was also a sharp increase. In 2014, the pesticide residue limit items had reached up to 470 . The severity of EU standard was the highest worldwide, and for pesticides that were not registered and executed in EU, zero index was implemented. Meanwhile, EU also released the regulations about reinforcing Chinese tea sampling and port management 


\section{B. Analysis on the Total Volume of Export and Proportion}

China has the riches tea resources in the world, and is also the first country that finds out and applies tea value. Currently,
China can rank top in both the tea planting area and the total output, and tea is one of the traditional commodities exported from China to EU, America and Japan.

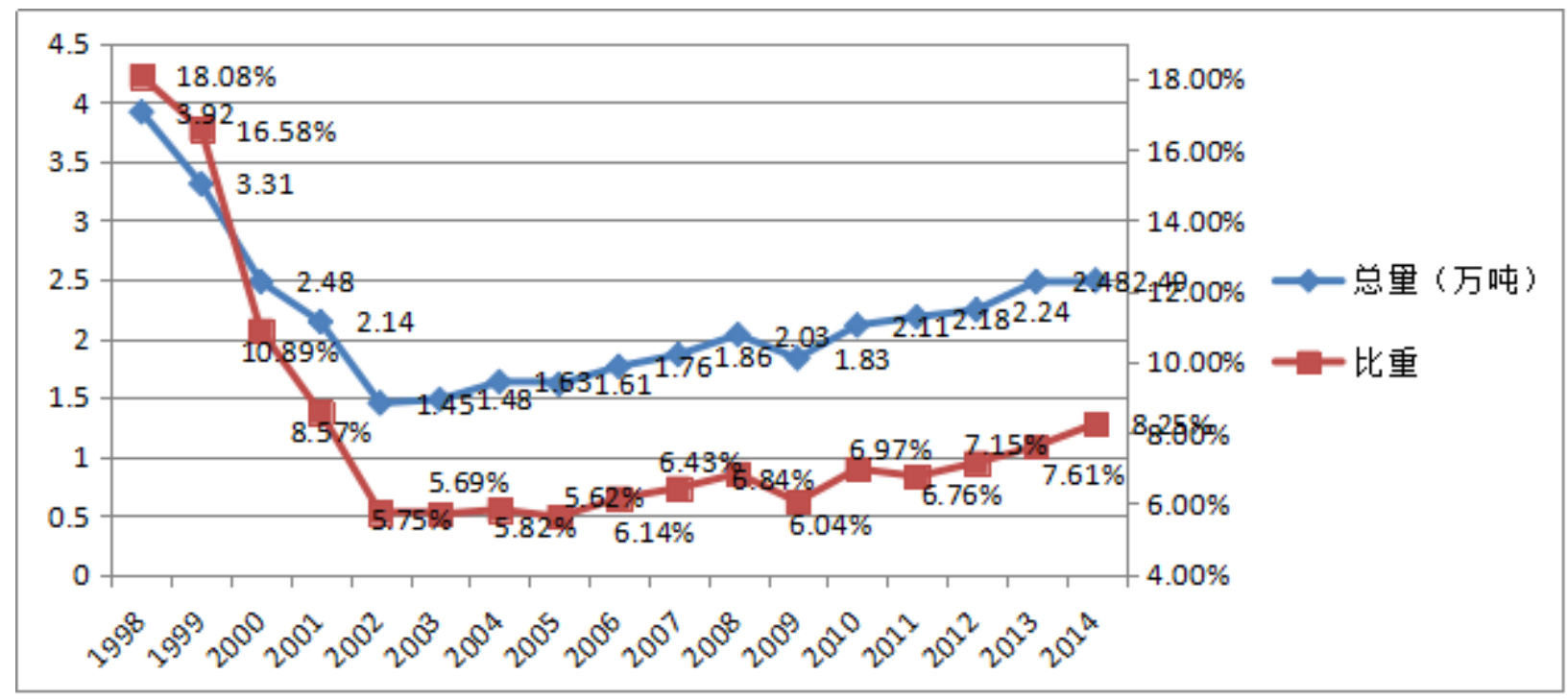

Fig. 1. Total Volume of Chinese Tea Exported to EU and the Proportion Variations

As can be seen in Figure 1, we can observe that from 1998 to 2014, the quantity of Chinese tea exported to EU and the export proportion had big variations. From 2000 to 2002, no matter it is the total quantity for the export to EU or the proportion, the situation was the most serious in these three years, and the reason is that EU released the new pesticide residues standards in 2000, of which the decrease in 2000 was the biggest, and the export volume was decreased to 24,800 tons from the original 33,100 tons, and was decreased by 8,300 the proportion for the export to EU was decreased from $16.58 \%$ to $10.89 \%$, and was decreased by $5.69 \%$. in 2009 , the quantity of tea exported to EU and the export proportion were decreased again, and the total volume of export was decreased to 18,300 tons from 20,300 tons, and the proportion was also decreased by $0.8 \%$ correspondingly, and the main reason is the 170 types of pesticides newly detected in tea in 2008 and the impact of financial crisis in 2008. From 2002 to 2014, the general trend for the changes in the export volume of Chinese team was relatively mild, but there was still no obvious trend of increase, and the export proportion was relatively stable than the export volume. a. Data Source: Chinese Customs Website

\section{EMPIRICAL ANALYSIS}

Regard the export trade volume as dependent variable Y, and the EU GDP per capita, the average unit price for exporting Chinese tea to EU, the EUR-RMB exchange rate, and the pesticide residue limit for imported tea of EU as Independent Variable X1-X4, and use the data from 1998 to 2014 to build regression model, and the statistical software selected thereby is SAS9.4.

\section{A. Explanations about the Variables in the Model}

\section{1) EU GDP Per Capita (X1)}

GDP per capita can reflect the consumption level and consumption demand of a country, and under the same conditions, the higher GDP is, the higher the consumption level will be, and this will benefit Chinese tea export, and then promote sales volume, so EU GDP per capita and the trade volume for the tea export of our country present positive relation. But on the other hand, with the increase in GDP per capita, the living level of residents in the country will be increased, and the products selected thereby will be pickier, and the low-end tea export of our country may be impacted. Thus, the function of GDP per capita for Chinese tea export is uncertain, which should depend on which aspect of function exerted thereby is bigger. 
2) Average unit Price for Chinese Tea Exported to EU (X2)

Under general conditions, the total demand will be decreased with the increase in unit price, but the export amount may be increased, which is decided by the export demand price elasticity, so the impact of unit price for the export of Chinese tea to EU is uncertain.

\section{3) Exchange Rate for the Exchange of EUR to RMB (X3)}

Under normal conditions, with the increase in EUR-RMB exchange rate, EUR value will be increased, and the price for EU people to buy our tea will be decreased, and the demand of our country will be increased for sure, so the total export amount will also be increased accordingly. But a period of time is requested for adjustment in the period of formation, so the impact of EUR-RMB exchange rate variable is uncertain.

\section{4) Agricultural Residual Limit Terms of EU for Imported} Tea (X4)

What we study is the impact of pesticide residue on Chinese tea export, so we need to find an explanatory variable that can quantize pesticide residue. Due to the increase in inspection terms, the trade cost of the exporter will be increased accordingly, and in order to reach to the strict requirements of EU, the exporter must input more in planting technology, export inspection, detection, authentication and other relevant expenses; the more the restrictions are, the lower the trade amount will be, so it is predicted that it has negative impact on trade volume.

\section{B. Data Source}

In this paper, EU GDP per capita is originated from World Bank Website. The total amount of tea export to EU and the total quantity are found through State Statistics Bureau. The average unit price is obtained through dividing the total amount of tea export to EU by the total quantity. EUR-RMB exchange rate is found through State Statistics Bureau and World Bank Website, and the data from 1998 to 2001 are obtained through calculating as per USD-EUR, and RMB exchange rate, and from 2002 to 2014, the average exchange rate for the current year is adopted. The pesticide residue limit terms of EU for imported tea are obtained through collecting EU orders of previous years.

Due to the constant expansion of EU, the relevant data mentioned in this paper before 2005 involve the earliest $15 \mathrm{EU}$ member countries, 27 member countries from 2005 to 2007 , and 28 EU countries from 2008 to 2014.

\section{Empirical Model Analysis and Construction}

As per Poyhonen and Tinbergen (1962), study the gravity model of international trade flow scale, and combine the independent variables selected thereby to establish the model expression as follows:

$$
Y=\beta_{0} \prod_{i=1}^{4} X_{i}^{\beta_{i}}
$$

After making the logarithm, it is:

$$
\ln (Y)=\ln \left(\beta_{0}\right)+\sum_{i=1}^{4} \beta_{i} \ln \left(X_{i}\right)
$$

Next, verify with the data after making the logarithm as per the model expression.

In the process of model establishment and regression diagnostics, since this paper confirms the impact of each independent variable on the trade volume of the dependent variable through mainly conducting t-test for the estimated value of regression coefficient, there are 5 problems that should be considered as follows:

Whether the normal assumption is established can be vital to whether it can pass t-test for $t$ distribution construction parameter estimation, and if it is not established, it will make ttest invalid, and it is planned to use normal test of goodness of fit to investigate the dependent variable of the model and the residual error terms of the final regression model, so as to ensure that it can be established;

Whether multicollinearity exits can be vital to the accuracy of parameter estimation, and if it exits, it will mix the coefficient estimated values for the independent variables of the regression equation with the effect of other independent variables, and cause certain error to the single estimation about the effect of certain independent variables, and it is planned to investigate through correlation test and variance inflation factor (VIF), and under appropriate conditions, select to delete independent variables for which the effect of dependent variables can be almost replaced with other independent variables;

Whether autocorrelation exists can be vital to whether the method of adopting regression model of panel data for time series data is feasible, and if it exits, it is requested to consider the use of time series analysis to replace the classic linear regression of cross-section data, and it is planned to investigate through Durbin-Watson inspection;

Whether outliers exist has no big impact on the effect explanation, but excessive outliers indicate that there may be certain deviations in model construction; besides, fewer outliers can also ensure the accuracy of model explanation in fitting, and it is planned to investigate through studentized residual error and Cook's D;

As for the fitting effect of model, under the condition of good fitting effect, its impact on effect explanation is smaller, but it can be selected as model variable and regarded as the references for possible predictions in the future, and it is planned to use R2, the adjusted R2 and Akaike information criteria, etc. for measurement.

\section{1) Model 1}

Firstly, conduct normal distribution test of goodness of fit for the trade volume of Chinese tea exported to EU after taking the logarithm, and roughly investigate whether the normal assumption is established. The statistic inspected by Kolmogrov-Smirnov is 0.10693 , and $p$ value is more than 0.15 ; the statistic inspected by Cramer-von Mises is 0.03416 , $p$ value is more than 0.25; the statistic inspected by Anderson-Darling 
is 0.25545 , and $\mathrm{p}$ value is more than 0.25 . The $\mathrm{p}$ value inspected by three tests of goodness of fit has all exceeded 0.05 , and cannot reject the original assumption that $\ln (\mathrm{z})$ obeys the normal distribution, so it can be preliminarily held that the normal assumption is established, and then use the test of goodness of fit again for the final residual error of the regression model, and confirm that the explanatory variable under Gauss-Markov classic assumption of the significance level of 0.05 obeys the conditional normal distribution, i.e., ensure that $\mathrm{F}$ inspection and $\mathrm{t}$-test in the regression are reasonable.
Place the four independent variables after taking the logarithm into the model, and obtain the test statistics about regression model $\mathrm{F}$, which is 66.29 , $\mathrm{p}$ value is less than 0.0001 , $\mathrm{R} 2$ is 0.9567 , and the adjusted R2 is 0.9423 , i.e., the model has passed $F$ inspection under the significance level of 0.05 , and explained the $95.67 \%$ variance of independent variable for the model, so it is held that the fitting effect of the model is good.

Further investigate the estimated value of parameters, which are as shown in the following table:

TABLE I REGRESSION RSULTS OF MODEL 1

\begin{tabular}{|c|c|c|c|c|c|}
\hline Variable & Parameter Estimation & Standard Error & $\mathrm{t}$ Value & Pr $>|\mathrm{t}|$ & $\begin{array}{c}\text { Variance Inflation } \\
\text { Factor }\end{array}$ \\
\hline Intercept & -2.65992 & 1.79503 & -1.48 & 0.1642 & 0 \\
\hline $\log 1$ & -0.23705 & 0.35053 & -0.68 & 0.5117 & 12.32557 \\
\hline $\log 2$ & 2.03539 & 0.23285 & 8.74 & $<.0001$ & 8.74327 \\
\hline $\log 3$ & -0.08985 & 0.42601 & -0.21 & 0.8365 & 2.21213 \\
\hline $\log 44$ & -0.40666 & 0.06218 & -6.54 & $<.0001$ & 3.99684 \\
\hline
\end{tabular}

As can be seen from the aforementioned result, the average unit price for China to export to EU and the pesticide residue limit of EU for imported tea have passed t-test of the model under the significance level of 0.05 , and it can be held that they have obvious impact on the dependent variable of the trade volume of tea exported from China to EU. But EU GDP per capita and $\mathrm{p}$ value for EUR-RMB exchange rate are more than 0.05 , so it can be held that, these two variables have no obvious impact on dependent variable under the significance level of 0.05 .

To some extent, in case of being merely restricted to investigating the impact of EU's pesticide residue limit for imported tea on the trade volume, the aforementioned regression model can be competent. But in consideration of the frequently occurred multicollinearity problems in economic index, it may impact t-test of parameter estimated value, and then impact the selection and explanation of variables, and then further investigate whether multicollinearity exists through correlation test and variance inflation factor.

Since the correlation coefficients for Pearson of $\ln (\mathrm{X} 1)$, $\ln (\mathrm{X} 2)$ and $\ln (\mathrm{X} 4)$ are respectively 0.87454 and 0.86035 , the correlation coefficients of Spearman are respectively 0.87990 and 0.89216, and $\mathrm{p}$ value for the correlation coefficients of Pearson and Spearman is less than 0.0001. Furthermore, variance inflation factor (VIF) for EU GDP per capita is 12.326 , which is slightly bigger than 10 . To sum up, it can be held that the four independent variables possess certain multicollinearity, and may impact the accuracy of t-test for the parameter estimation, and the correlation test can also show the pesticide residue limit of EU for imported tea and the average unit price, and better reflect the impact of EU GDP per capital variable on trade volume within the international trade of tea, so it is considered to delete the fact that EU GDP per capital variable, so as to ensure that multicollinearity won't generate obvious errors of t-test result. The other important reason for deleting GDP is that EU GDP per capital presents positive relation with the export trade of tea in our country, but the coefficients of regression model are negative, so this variable cannot be used.

\section{2) Model 2}

After deleting EU GDP per capita, obtain the test statistic for regression model $\mathrm{F}$, which is 92.07 , and $\mathrm{p}$ value is less than 0.0001 , and R2 is 0.9551 , and the adjusted R2 is 0.9447 , i.e., the model has passed F-test under the significance level of 0.05 , and explained $95.51 \%$ variance of independent variable for the model, so it can be held that the fitting effect of the model is good. Meanwhile, AIC for the Model 1 is -72.0956 , but AIC for Model 1 is -70.7315 , and as per Akaike information criteria (the smaller the better) and the adjusted R2 principle (the bigger the better), it can be held that the fitting effect for Model 2 is better than Model 1 .

Further investigate parameter estimated value, which is as shown in the following table:

TABLE II REGRESSION RESULTS OF MODEL 2

\begin{tabular}{|c|c|c|c|c|c|}
\hline Variable & $\begin{array}{c}\text { Parameter } \\
\text { Estimation }\end{array}$ & Standard Error & $\mathrm{t}$ Value & $\operatorname{Pr}>|\mathrm{t}|$ & $\begin{array}{c}\text { Variance Inflation } \\
\text { Factor }\end{array}$ \\
\hline Intercept & -3.52615 & 1.23102 & -2.86 & 0.0133 & 0 \\
\hline $\log \mathrm{x} 2$ & 1.90726 & 0.13251 & 14.39 & $<.0001$ & 2.95472 \\
\hline $\log 3$ & -0.28905 & 0.30128 & -0.96 & 0.3549 & 1.15458 \\
\hline $\log \mathrm{x} 4$ & -0.42847 & 0.05204 & -8.23 & $<.0001$ & 2.92157 \\
\hline
\end{tabular}

As can be seen from the aforementioned result, the average unit price for China to export to EU and the pesticide residue limit of EU for imported tea can still all pass t-test under the

significance level of 0.05 , and it can be held that the their impact on the dependent variable of the trade volume for China to export tea to EU is obvious. But $\mathrm{p}$ value for EUR-RMB 
exchange rate is 0.3549 , which is more than 0.05 , so it can be held that the impact of such independent variable on dependent variable under the significance level of 0.05 is not obvious.

Further investigate multicollinearity through variance inflation factor (VIF), and all the variance inflation factors of these three independent variables are less than 10 , and it can be held that, although there is certain correlation between the average unit price for China to export to EU and the pesticide residue limit for imported tea of EU, when they are simultaneously placed in the regression model, there is no serious multicollinearity, and will cause no obvious errors to the result of parameter estimation. To sum up, it can be held that the problem of multicollinearity can be better relieved through deleting the independent variable of EU GDP per capita.

\section{3) Model 3}

In Model 2, p value for EUR-RMB exchange rate t-test is 0.3549 , and it can be held that the impact of such independent variable on the trade volume of the dependent variable is not obvious under the level of 0.05 . besides, through studentized residual error and Cook's D, it can be seen that, the studentized residual error for the observation value in 2002 was -2.212, and
Cook's D was 0.834 , which were all higher than that of other observation values, especially Cook's D, which had exceeded the critical value $4 / n=0.235$. Thus, from the perspective of fitting, the fitting effect of Model 2 still needs to be further improved; meanwhile, it has also eliminated indistinctive disturbance of independent variables, and the parameter estimation after improving the model will also be more accurate accordingly.

Delete EUR-RMB exchange rate that shows no obvious impact on trade volume, and then obtain the test statistic of regression model $\mathrm{F}$, which is 138.44 , $\mathrm{p}$ value is less than 0.0001 , and R2 is 0.9519 , and the adjusted R2 is 0.9450 , i.e., the model has passed F-test under the significance level of 0.05 , and also explained $95.19 \%$ variance of independent variable for the model, so it can be held that the fitting effect of the model is good. Meanwhile, AIC for the Model 1 is -72.9327, but AIC for Model 2 is -72.0956 , and as per the adjusted R2 principle (the bigger the better), it can be held that the fitting effect for Model 3 is better than Model 2 and Model 1.

Further investigate parameter estimated value, which is as shown in the following table:

TABLE III REGRESSION RESULTS OF MODEL 3

\begin{tabular}{|c|c|c|c|c|c|}
\hline Variable & $\begin{array}{c}\text { Parameter } \\
\text { Estimation }\end{array}$ & $\begin{array}{c}\text { Standard } \\
\text { Error }\end{array}$ & $\mathrm{t}$ Value & $\operatorname{Pr}>|\mathrm{t}|$ & $\begin{array}{c}\text { Variance } \\
\text { Inflation Factor }\end{array}$ \\
\hline Intercept & -4.43112 & 0.78874 & -5.62 & $<.0001$ & 0 \\
\hline $\log \mathrm{x} 2$ & 1.95232 & 0.12355 & 15.8 & $<.0001$ & 2.58353 \\
\hline $\log \mathrm{x} 4$ & -0.44545 & 0.0488 & -9.13 & $<.0001$ & 2.58353 \\
\hline
\end{tabular}

As can be seen from the aforementioned result, both the coefficient and constant terms of all independent variables have passed t-test of the model under the significance level of 0.05 , and it can be held that their impact on the dependent variable of

$$
\begin{gathered}
\ln (Y)=-4.43112+1.95232 \times \ln \left(X_{2}\right)-0.44545 \times \ln \left(X_{4}\right) \\
(0.78874)(0.12355)
\end{gathered}
$$

Of which, the number in brackets is the standard error for the independent variable estimated value of regression model.

\section{4) Regression Diagnostics}

Regression diagnostics will be conducted as per the final model (Model 3) selected through multicollinearity and the fitting effect.

Firstly, investigate whether normal assumption is established. Conduct normal distribution test of goodness of fit for residual errors of regression model, and the statistics inspected by Kolmogrov-Smirnov is 0.15541 , p value is more than 0.15 ; the statistics inspected by Cramer-von Mises is 0.04530 , and $\mathrm{p}$ value is more than 0.25 ; the statistics inspected by Anderson-Darling is 0.27812 , and p value is more than 0.25 . The $\mathrm{p}$ value for three tests of goodness of fit have all exceeded 0.05 and cannot reject the original assumption that residual error obeys the normal distribution, so it can be held that the normal distribution assumption is reasonable, and it is reasonable to adopt t-test to conduct significance test. trade volume for Chinese tea exported to EU is obvious. All the variance inflation factors (VIF) are below 10, and it can be held that, there is no obvious multicollinearity, and the expression of Model 3 finally obtained thereby is:

Secondly, investigate the autocorrelation of residual error, and adopt Durbin-Watson test for Model 3, D statistic is 1.716, and $p$ value is 0.1171 for taking positive autocorrelation as the original assumption, and $\mathrm{p}$ value is 0.8829 for taking negative autocorrelation as the original assumption, and both of them are more than 0.05 , so it can be held that, there is no autocorrelation between residual errors, and it is reasonable to adopt regression method of panel data.

Finally, investigate outliers. The maximum absolute value for studentized residual errors occurred in the observation value of 2001, which was 2.059, and was below the critical value 3. The maximum Cook's D also occurred in the observation value of 2001, which was 0.297 , and it is the only observation exceeding the critical value $4 / \mathrm{n}=0.235$; in consideration of the fact that the amount exceeded by 0.297 is few, and the only outlier has a relatively small impact on parameter estimation, Model 3 is superior to Model 2 and Model 1 considering the quantity of outliers and the outlier degree, so it can be temporarily held that this model is the reasonable model. 
To sum up, the finally obtained model expression is:

$$
\ln (Y)=-4.43112+1.95232 \times \ln \left(X_{2}\right)-0.44545 \times \ln \left(X_{4}\right)
$$

$\mathrm{Y}$ is the dependent variable (the trade volume for exporting Chinese tea to EU), $\mathrm{X} 2$ is the independent variable (the average unit price for EU to import from China), and $\mathrm{X} 4$ is the independent variable (the pesticide residue limit of EU for imported tea). As can be seen from the aforementioned result, it can be obtained that, the average unit price for exporting Chinese tea to EU has small price elasticity of demand; the pesticide residue limit is the same with our expected result, and the impact on the trade volume for exporting Chinese tea to EU.

\section{COUNTERMEASURE SUGGESTIONS}

\section{A. Reinforce Consciousness of Citizens}

Whether the citizens of the exporter have green economy awareness will directly impact whether the exported products of the enterprise can meet the international standard. There is no doubt that, Chinese peasants lack in environmental protection planting awareness, and our country is short of the positive guidance about environmental protection planting. Thus, in order to promote the export competitiveness, it is requested to reinforce the green economic awareness of citizens, which relies not only on the exported products meeting the standard, but also the pesticide residue for tea consumed by citizens of its own country meeting the standard. The relevant department of the government should conduct pointed publicity considering the disadvantages and green economy advantages in tea export and the production process of tea peasants, so as to constantly reinforce the green economic awareness of citizens; in order to encourage peasants to practice the environmental protection planting of tea, the government can also release some preferential subsidy policies for environmental protection planting. The enterprises can conduct targeted training guidance specific to the senior of the company, and also periodically carry out energy-saving and environmental protection training for grass-roots employees, so as to ensure the value of green economy from the senior to the grass roots of the company. The promotion of citizens' green economy awareness will improve the tea quality, so as to meet the international standard, and the green trade barriers of various countries will also be decreased.

\section{B. Improve Pesticide Residue Limit Standard and Increase Pesticide Residues Inspection Technology}

Currently, the pesticide residue standard of our country is far less than European and American developed countries, and the standard system is backward and loose, which has caused the failure for lots of tea to reach to the EU standard and become problematic tea. Our country should dock with international standard, for instance, refer to CAC standard, modify the existing standard of our country, perfect the pesticide residue standard system for the tea of our country, and make Chinese tea more competitive in the international market. The government and the enterprise should increase the investment science and technology strength in a deeper layer, so as to improve the inspection control capacity of pesticide residue in our country, and ensure export standard.

\section{Implement Non-dull trade, and Reach to Avoided-type Crossing}

Except for considering quality safety, EU countries adopt such strict pesticide residue barrier mostly for adopting measures to restrict the entrance of foreign products into the market of its own country. Generally it refers to "being strict to others and being gentle to itself". In view of this situation, it is applicable to cooperating with transnational corporations or the importer. By virtue of its own tea resource advantages in combination with the preferential policies of our country, attract financing, realize localization production, and then cross the green trade barriers of importing country; China can also implement transnational management and joint venture with the purchasing party, fully use the advantageous technologies of the purchasing party, the trade channel and quality specification, produce and sell better products to EU.

\section{REFERENCES}

[1] Jiao Zhiyue and Zhao Lingyun. Impact of Pesticide Residue limit for EU Tea on Chinese Tea Export and the Countermeasures [J]. World Agriculture, 2015, 434 (6): 132-136+22.

[2] Wang Wenjun and Chen Qiong. Research about the Pesticide Residue limit Standard of EU Newest Food [J]. WTO Economic Herald, 2015, 137 (2): 90-92.

[3] Ma Qiang and Qi Chunjie. Empirical Analysis about the Impact of Pesticide Residue limit Standard on the Export Trade of Citrus in the Mainland of China [J]. Journal of Huazhong Agricultural University (Social Science Version), 2013, 108 (6): 53-58.

[4] Guo Qiuting. Impact about the Impact of Green Trade Barriers on the Tea Export of Hunan Province [D]. Guangzhou: Guangdong University of Foreign Studies, 2017. 